\title{
NANISMO HIPOFISÁRIO EM UM CANINO: ACHADOS CLÍNICOS E LABORATORIAIS
}

\author{
PITUITARY DWARFISM IN A CANINE: \\ CLINICAL AND LABORATORIAL FINDINGS
}

Luiz Fernando Jantzen Gaspar

Anne Santos do Amaral ${ }^{2}$

- RELATO DE CASO -

\section{RESUMO}

Relata-se um caso de nanismo hipofisário em um canino da raça Pastor Alemão, fêmea, com 14 meses de idade. Descreve-se sinais clínicos e dosagem das concentrações plasmáticas de hormônio do crescimento (GH) antes e após a estimulação $\alpha$-adrenérgica com cloridrato de xilazina. $\mathrm{O}$ nível máximo de $\mathrm{GH}$ plasmático pós-estímulo foi $1 \mathrm{ng} / \mathrm{dl}$.

Palavras-chave: Hipossomatotrofismo, nanismo, hipofise, canino.

\section{SUMMARY}

This case report is about dwarfism in a German Shepherd dog, female, 14 months old. Clinical signals are described. The endocrinologic investigation was realized by dosages of plasma levels of growth hormone, pre and post xilazine estimulation. The maximal level of $\mathrm{GH}$ postestimulation was $1 \mathrm{ng} / \mathrm{dl}$.
Key words: Hyposomatotropism, dwarfism, pituitary, canine

\section{INTRODUÇÃO}

Etiologia: o nanismo é uma condição caracterizada pela baixa estatura. Este fato pode ser hereditário ou conseqüente a processos patológicos ocorridos durante a vida intra-uterina e pós-natal, os quais impedem o completo desenvolvimento do potencial de crescimento geneticamente determinado. Apenas a última condição é verdadeiramente denominada de nanismo (EIGENMANN, 1992).

De acordo com FELDMAN \& NELSON (1987), o nanismo hipofisário em caninos está freqüentemente associado com uma distensão cística congênita ou com a persistência da porção intra-selar do ducto craniofaringeal ou bolsa de Rathke.

Segundo Rao \& Bhat apud FELDMAN \& NELSON (1987), embora o nanismo seja raro, os cistos são relativamente comuns em cães. A teoria de que a distensão do cisto tenha como causa primária a destruição da adeno-

\footnotetext{
${ }^{1}$ Médico Veterinário, Professor Assistente, Departamento de Clínicas, Faculdade de Medicina Veterinária da Universidade Federal de Pelotas, Campus Universitário s/no CEP 96100-000. P6s-graduando em Medicina Veterinária, Universidade Federal de Santa Maria (UFSM). Autor para correspondência.
}

${ }^{2}$ Médico Veterinário, pós-graduando em Medicina Veterinária, UFSM. 
hipófise não está ainda esclarecida. Como hipótese alternativa, \& proposta uma insuficiência primária na diferenciação das células da adeno-hipófise em células secretoras de hormônio trófico (Eigenmann apud FELDMAN \& NELSON, 1987). RANDOLPH \& PETERSON (1994) descreveram que não é exato se a expansão do cisto pituitário destrói o tecido adjacente da adeno-hipofise ou se a capacidade secretória das células da adeno-hipófise é que origina o cisto. A análise do fluido cístico obtido de ratos mostrou que o material proteináceo osmoticamente ativo pode atrair água e contribuir para o crescimento do cisto (Benjamin apud FELDMAN \& NELSON, 1987). O nanismo hipofisário pode desenvolverse devido à perda de ação periférica do $\mathrm{GH}$, resultante de uma anormalidade estrutural do hormônio (Kovarski et al. e Valenta et al. apud FELDMAN \& NELSON, 1987); por incapacidade do GH em aumentar as concentrações de somatomedina (Laron et al. e Merimee et al. apud FELDMAN \& NELSON, 1987) ou à perda de resposta do tecido alvo à somatomedina (Lanes et al. apud FELDMAN \& NELSON, 1987), devido a um defeito nos receptores de membrana.

Várias raças caninas são mais suscetíveis ao desenvolvimento de nanismo hipofisário. Nas raças Pastor Alemão e Carelian bear-dog o hipossomatotrofismo é transmitido hereditariamente por um gene autossômico recessivo, o qual está associado com a distensão do ducto craniofaringeal (bolsa de Rathke). Apesar de existir predisposição racial, não há evidências de predileção por sexo (MULLER et al., 1985; RANDOLPH \& PETERSON, 1994).

Exame Físico: Os animais afetados são freqüentemente de tamanho normal durante os primeiros dois meses de vida, após os quais apresentam um ritmo de crescimento mais lento que o dos seus irmãos de ninhada. Com três a quatro meses de idade, o animal afetado é visivelmente $o$ menor da ninhada e certamente nunca atingirá as dimensões de um adulto (MULLER et al., 1985; COLES, 1986; Walker apud FELDMAN \& NELSON, 1987). Anormalidades ósseas mandibulares, como o prognatismo, podem ser evidencidas durante o exame clínico (CHASTAIN, 1993). A erupção dos dentes permanentes apresenta-se retardada, mas a dentição é normal (COLES, 1986; FELDMAN \& NELSON, 1987).

O sinal dermatológico mais notável é a retenção da "lanugem" ou pelagem secundária com a concorrente perda da pelagem primária (CHASTAIN, 1993). Os pêlos secundários são facilmente retirados, e a alopecia simétrica bilateral desenvolve-se gradualmente. A perda de pêlos está confinada a áreas de contato com roupas, coleiras e regiões de atrito no decúbito. Eventualmente o tronco inteiro e extremidade proximal dos membros tornam-se alopécicos, com a pelagem primária permanecendo somente na face $e$ extremidade distal dos membros. A pele inicialmente é normal, mas com o tempo torna-se progressivamente hiperpigmentada, delgada, hipotônica e escamosa (MULLER et al., 1985; FELDMAN \& NELSON, 1987; EIGENMANN, 1992; RANDOLPH \& PETERSON, 1994). Os comedos, pápulas e piodermite secundária freqüentemente aparecem no anão adulto. $O$ desenvolvimento secundário de hipotireoidismo e hipoadrenocorticismo depende da severidade do dano causado à glândula pituitária.

Avaliação endocrinológica: Os níveis plasmáticos basais do $\mathrm{GH}$ em cães normais apresentam uma variação de $1,5 \pm 1,2 \mathrm{ng} / \mathrm{ml}$ a $4,3 \pm 1,1 \mathrm{ng} / \mathrm{ml}$ (MULLER et al., 1985; Eigemann apud FELDMAN \& NELSON, 1987). Como os níveis basais do GH em anões pituitários e cães hipofisectomizados podem aproximar-se destes valores (Eigenmann, Scott et al., Parker \& Scott, Eigenmann \& Patterson apud FELDMAN \& NELSON, 1987), recomendase, para fins diagnósticos, avaliar a capacidade secretória do GH após o estímulo da hipófise.

A estimulação com substâncias $\alpha$-adrenérgicas é utilizada para avaliar a capacidade secretória de $\mathrm{GH}$. As amostras são obtidas nos tempos $0,15,30,45,60$ e 90 minutos. De acordo com HAMPSHIRE \& ALTSZULER (1981) a administração de xilazina $(100-300 \mu \mathrm{g} / \mathrm{kg})$ ou de clonidina $(3-30 \mu \mathrm{g} / \mathrm{kg})$, via endovenosa, estimula a secreção de $\mathrm{GH}$, atingindo um limiar máximo de concentração plasmática em torno de 15 a 30 minutos após o início do teste. Para CHASTAIN (1993), a deficiência de GH está caracterizada quando os resultados dos níveis plasmáticos pós-estimulação forem inferiores a $2 \mathrm{ng} / \mathrm{ml}$.

\section{RELATO DO CASO}

Um cão da raça Pastor Alemão, fêmea, com 14 meses de idade e $6 \mathrm{~kg}$ de peso corporal, foi atendido no Hospital de Clínicas Veterinárias da UFSM, com a queixa de interrupção do crescimento observado a partir do $4^{\circ}$ mês de vida. $O$ animal apresentava estatura inferior aos irmãos de ninhada, pêlos macios e lanudos (Figura 1). O proprietário informou que o cão descendia de animais com estatura normal e portadores de registro genealógico.

Sinais clínicos: ao exame clínico verificou-se tamanho e peso inferiores à idade cronológica; permanência de pelagem secundária (lanugem), notavelmente presente em toda superficie corporal; desenvolvimento de alopecia simétrica bilateral nas regiões isquiáticas; pele adelgaçada, hipotônica, escamosa e com hiperpigmentação nas regiơes peitoral e abdominal; presença de comedos próximos às articulações fêmur-tíbio-rotulianas; presença de prognatismo superior, persistência dos dentes caninos decíduos e vocalização de filhote. 




Figura 1. Aspecto geral do cão Pastor Alemão com nanismo hipofisário aos 14 meses de idade. Destaca-se o pequeno porte físico e a permanência de pelagem secundária (lanugem).

Determinação do hormônio de crescimento (GH): colheu-se uma amostra de $4 \mathrm{ml}$ de sangue da jugular, para obtenção de plasma e determinação do $\mathrm{GH}$ basal. Após, administrou-se cloridrato de xilazina ${ }^{\mathrm{a}}(300 \mu \mathrm{g} / \mathrm{kg})$ por via endovenosa, realizando-se novas colheitas de sangue aos $15,30,45,60$ e 90 minutos, para a quantificação do $\mathrm{GH}$ pós-estímulo. A concentração basal de $\mathrm{GH}$ plasmático foi $0,3 \mathrm{ng} / \mathrm{ml}$ e, no pós-estímulo, $1 \mathrm{ng} / \mathrm{ml}$ aos 15 minutos, $0,5 \mathrm{ng} / \mathrm{ml}$ aos 30 e 45 minutos, $0,4 \mathrm{ng} / \mathrm{ml}$ aos 60 minutos e $0,5 \mathrm{ng} / \mathrm{ml}$ aos 90 minutos. Para a aferição do $\mathrm{GH}$ plasmático foi adotada a técnica de radioimunoensaio (base sólida) desenvolvida em laboratório autônomo ${ }^{\mathrm{b}}$. Os resultados obtidos foram comparados graficamente às respostas ao teste de estimulação com xilazina em cães normais segundo HAMPSHIRE \& ALTSZULER (1981) e apresentados na Figura 2.

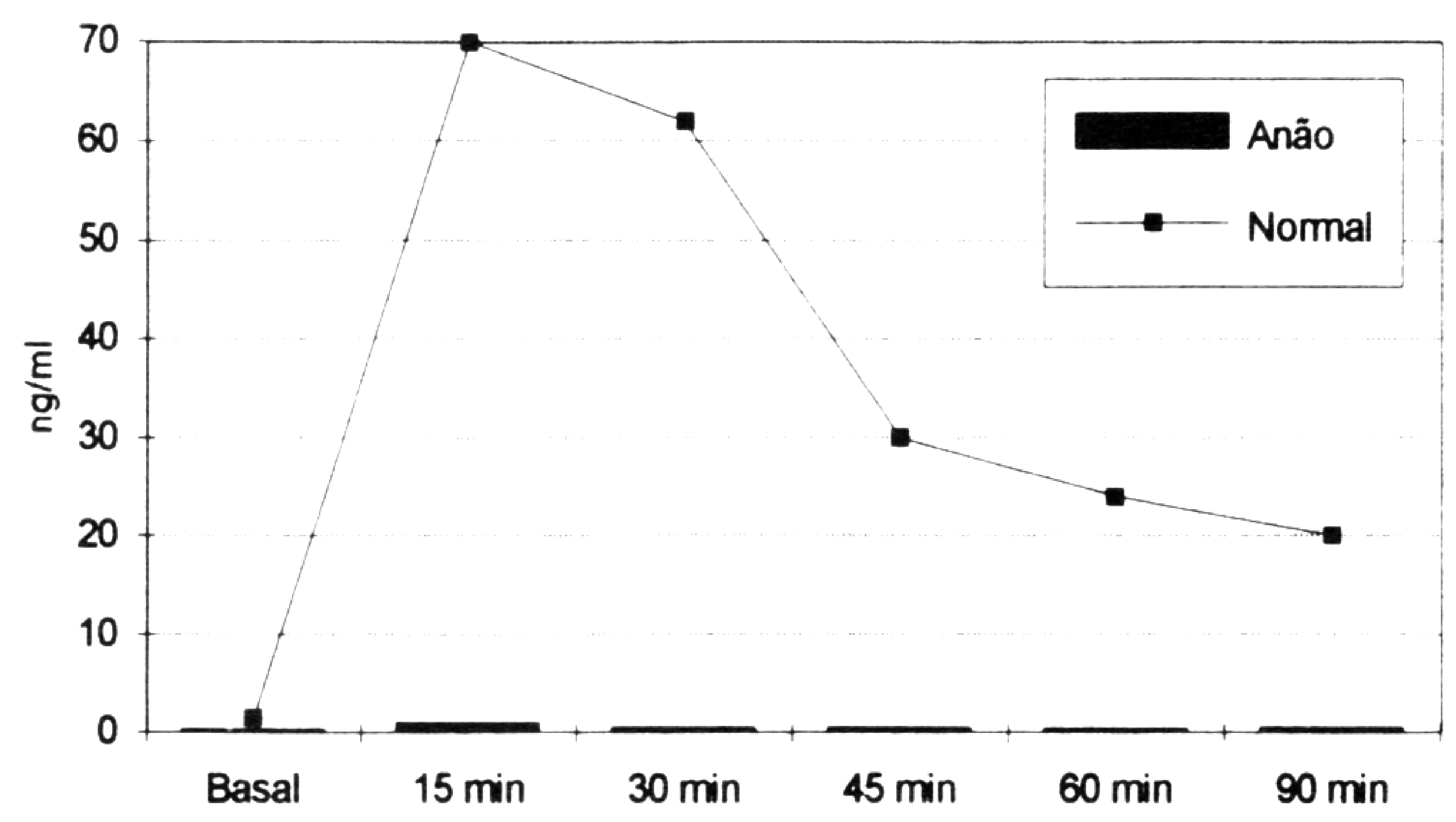

Figura 2. Demonstração gráfica dos níveis plasmáticos de $\mathrm{GH}$ basal e após a estimulação $\alpha$-adrenérgica em cão com nanismo hipofisário, comparado a um animal normal.

\section{DISCUSSÃO E CONCLUSÃO}

Esta descrição apresenta um caso de nanismo hipofisário em um cão da raça Pastor Alemão. MULLER et al. (1985) e RANDOLPH \& PETERSON (1994), referiramse à raça Pastor Alemão como uma das mais incidentes.

Manifestações clínicas como ritmo de crescimento lento a partir do $4^{\circ}$ mês de vida, caracterizado pela estatura inferior aos irmãos de ninhada foram descritas por MULLER et al. (1985), COLES (1986) e Walker apud FELDMAN \& NELSON (1987).

O prognatismo, observado neste caso, foi citado por CHASTAIN (1993) como uma anormalidade óssea mandibular evidente no exame clínico. A permanência de pêlos secundários e a concorrente perda da pelagem primária foram também relatados por CHASTAIN (1993), o qual referiu-se a este sinal clínico como a alteração dermatológica mais notável. Outras alterações dermatológicas encontradas, tais como: alopecia, comedos, pele adelgaçada, hipotônica, escamosa e hiperpigmentação nas regióes peitoral e abdominal estão de acordo com a descrição de MULLER et al. (1985), FELDMAN \& NELSON (1987), EIGEMANN (1992) e RANDOLPH \& PETERSON (1994).

A permanência dos caninos decíduos aos 14 meses sugere um retardo na erupção dos dentes conforme afirmaram COLES (1986) e FELDMAN \& NELSON (1987).

O nível basal de $\mathrm{GH}$ plasmático verificado no presente relato foi inferior aos valores normais propostos por MULLER et al. (1985) e Eigemann apud FELDMAN \& NELSON (1987). Os níveis de GH pós-estímulo foram inferiores a $2 \mathrm{ng} / \mathrm{ml}$, condição que caracteriza a deficiência de GH segundo CHASTAIN (1993).

\section{FONTES DE AQUISIÇÃO}

a - Rompun: Bayer do Brasil, São Paulo, SP.

b - Imuno Pesquisas Clínicas Ltda.: Vicente Fontoura, 2352. Porto Alegre, RS.

\section{REFERÊNCIAS BIBLIOGRÁFICAS}

CHASTAIN, C. B. Sistemas endócrino e metabólico. In: HOSKINS, J. D. Pediatria veterinária. São Paulo: Manole, 1993. Cap. 9, p. 271-293.

COLES, E. H. Veterinary clinical pathology. Philadelphia: Saunders, 1986. Cap. 11: Adrenal and pituitary function: p. 217-225.

EIGENMANN, J.E. Moléstias hipotalâmico-pituitárias. In: ETTINGER, S.J Tratado de medicina interna. Rio de Janeiro: Guanabara-Koogan, 1992. V. 3, Cap. 93, p. 1661-1682.

FELDMAN, E. C., NELSON, R. W. Canine and feline endocrinology and reproduction. Philadelphia: Saunders, 1987. Cap. 2: Growth hormone: p. 29-54. 
HAMPSHIRE, J. , ALTSZULER, N. Clonidine or xylazine as provocative tests for growth hormone secretion in the dog. American Journal of Veterinary Research, v. 42, n. 6, p. 1073-1076, june 1981.

MULLER, G. H., KIRK, R. W., SCOTT, D. W. Dermatologia dos pequenos animais. 3.ed. São Paulo: Manole, 1985. Cap. 10:
Endocrinologia cutânea: p. 517-588.

RANDOLPH, J. F., PETERSON, M. E. Hypotalamus and pituitary gland. In: BIRCHARD, S. J., SHERDING, R. G. Saunders manual of small animal practice. Philadelphia: Saunders, 1994. Section 4, cap. 6, p. 263-271. 